\title{
Densities and porosities of meteoroids
}

\author{
P. B. Babadzhanov and G. I. Kokhirova
}

Institute of Astrophysics, Tajik Academy of Sciences, Dushanbe 734042, Tajikistan

e-mail: [P.B.Babadzhanov; Kokhirova2004]@mail.ru

Received 25 June 2008 / Accepted 13 November 2008

\section{ABSTRACT}

\begin{abstract}
Using a physical theory of meteors and on the basis of the results of double-station photographic observations of meteors in Dushanbe (Tajikistan), Kiev, and Odessa (Ukraine), the mean mineralogical and bulk densities of meteoroids belonging to nine meteoroid streams and sporadic background are determined. The mean mineralogical densities $\delta_{\mathrm{m}}$ of meteoroids range from $2.2 \mathrm{~g} \mathrm{~cm}^{-3}$ (Perseids) to $3.4 \mathrm{~g} \mathrm{~cm}^{-3}$ (Quadrantids, $\delta$-Aquarids, and $\alpha$-Capricornids). The meteoroid bulk densities $\delta$, which were determined according to the theory of quasi-continuous fragmentation of meteoroids in the Earth's atmosphere, vary from $0.4 \mathrm{~g} \mathrm{~cm}^{-3}$ (Leonids) to $2.9 \mathrm{~g} \mathrm{~cm}^{-3}$ (Geminids). Using the relation between bulk density and mineralogical density the porosity of meteoroids was estimated. The Geminid meteoroids are found to have the lowest porosity, while the Leonid and Draconid meteoroids have the most porous structure (83\%). These results confirm the porous-structure nature of meteoroids' parent bodies i.e. comets and asteroids.
\end{abstract}

Key words. meteors, meteoroids - techniques: photometric

\section{Introduction}

The investigation of meteoroids' physical parameters is of significant interest in understanding the physical nature of meteoroids' parent bodies i.e. Near-Earth Objects. It is also important scientifically and because asteroids and comets represent a longterm danger to the biosphere and human kind as they repeatedly transfer the Earth's orbit.

It has been proved that the majority of meteoroids are products of disintegration of cometary nuclei and asteroids due to their mutual impacts. Thus, we can say definitely that meteoroids are remnants of comets and asteroids. Therefore, the determination of orbits and physical characteristics of meteoroids is important for both meteor astronomy and understanding the physical properties of the meteoroids' parent bodies.

Bulk and mineralogical (grain) densities relate to important physical parameters of meteoroids. The opinion that meteoroids have low bulk densities equal on average to $0.26 \mathrm{~g} \mathrm{~cm}^{-3}$ (Jacchia et al. 1967; Verniani 1967, 1969, 1973) was widely accepted until more recently.

On the basis of observational data about the heights of approximately 6000 bright meteors produced by meteoroids in a wide mass range from $10^{-4} \mathrm{~g}$ to $10^{8} \mathrm{~g}$, Ceplecha \& McCrosky (1976) and Ceplecha (1988) concluded, that according to their composition and structure, the meteoroids form four main groups: I - ordinary chondrites, with a mean density of $3.7 \mathrm{~g} \mathrm{~cm}^{-3}$; II - carbonaceous chondrites, with a mean density $2.1 \mathrm{~g} \mathrm{~cm}^{-3}$; IIIA - dense cometary material, with a mean density $0.75 \mathrm{~g} \mathrm{~cm}^{-3}$; and IIIB - ordinary cometary material, with a mean density $0.4 \mathrm{~g} \mathrm{~cm}^{-3}$. These results were confirmed by Ceplecha et al. (1993) in determining the bulk density by applying the "gross" fragmentation model of meteoroids.

The difference between these evaluations of meteoroid densities could be caused not only by the different methods used, but also because the method of determining bulk densities from drag and luminosity equations is applicable only to single non-fragmenting meteoroids, which cannot be considered to be accurate in our case.

The discrepancy between measurements of the bulk densities of meteoroids by different methods implied that the physical theory of meteors had to be improved by taking into account meteoroid fragmentation in the Earth's atmosphere (Levin 1962, 1963; Lebedinets 1980; Bronshten 1981; Novikov et al. 1984; Babadzhanov et al. 1988; Ceplecha \& McCrosky 1992; Ceplecha et al. 1993; Ceplecha 1995).

It has been established that fragmentation is a widespread type of ablation for the majority of meteoroids that produce meteors registered by photographic, TV, and radar methods. By analysing photographic observations of meteors, the following four main types of meteoroid fragmentation have been identified (Levin 1962): 1) the decay of a meteoroid into significantly large pieces of non-fragmenting debris; 2) the progressive disintegration of the original meteoroid into fragments that continue to crumble into smaller debris; 3 ) the quasi-continuous fragmentation, which involves a gradual release of the smallest fragments from the surface of a parent meteoroid and their subsequent evaporation; and 4) the simultaneous ejection of a large number of small particles that produce meteor flares.

Photographic observations of meteors have indicated that, along the meteor trajectory, the fragmentation of the first and fourth types may occur more than once. It is probable that a meteoroid may undergo different combinations of these fragmentation forms in the atmosphere.

\section{Mineralogical density of meteoroids}

The meteoroid density determined using the equation of heat conductivity was reffered to as the grain (or mineralogical) density of meteoroid substance, which can differ from its bulk density in the presence of voids and volatile inclusions, and porous structure (Ceplecha 1958; Benyuch 1968; Bronshten 1981). 
Table 1. Physical parameters and function $f\left(\delta_{\mathrm{m}}\right)$ for different materials.

\begin{tabular}{llllc}
\hline \hline Material & $\begin{array}{l}\delta_{\mathrm{m}}, \\
\mathrm{g} \mathrm{cm}^{-3}\end{array}$ & $\begin{array}{l}c \times 10^{7}, \\
\mathrm{erg} \mathrm{g}^{-1} \mathrm{deg}^{-1}\end{array}$ & $\begin{array}{l}\lambda, \\
\mathrm{erg} \mathrm{s}^{-1} \mathrm{~cm}^{-1} \mathrm{deg}^{-1}\end{array}$ & $f\left(\delta_{\mathrm{m}}\right)$ \\
\hline Brick (Kizel'gur) & 0.40 & 0.75 & $9.3 \times 10^{3}$ & 8.72 \\
Sand (river) & 1.52 & 0.70 & $2.7 \times 10^{4}$ & 9.39 \\
Sandstone & 2.45 & 0.93 & $1.7 \times 10^{5}$ & 9.93 \\
Schist & 2.67 & 0.71 & $1.5 \times 10^{6}$ & 10.13 \\
Granite & 2.70 & 0.65 & $2.5 \times 10^{5}$ & 10.15 \\
Basalt & 2.90 & 0.85 & $2.0 \times 10^{5}$ & 10.20 \\
Fluorit & 3.20 & 0.85 & $1.0 \times 10^{6}$ & 10.25 \\
Fyalit & 4.40 & 0.55 & $2.0 \times 10^{6}$ & 10.52 \\
Gematit & 5.26 & 0.61 & $2.4 \times 10^{5}$ & 10.66 \\
Arsenopirit & 6.07 & 0.43 & $3.8 \times 10^{6}$ & 10.82 \\
Iron* & 7.60 & 0.44 & $7.3 \times 10^{6}$ & 11.00 \\
\hline
\end{tabular}

*Values of $f\left(\delta_{\mathrm{m}}\right)$ is given for $\Lambda=0.75$.

The equation of heat conductivity may be written in the following form:

$$
\frac{2 T_{B}\left(\lambda \delta_{\mathrm{m}} c\right)^{1 / 2}}{\Lambda}=\frac{V_{0}^{5 / 2} \rho}{\left(b \cos Z_{R}\right)^{1 / 2}},
$$

where $T_{B}$ and $\Lambda$ are the temperature of a meteoroid frontal surface and the heat transfer coefficient in the beginning of evaporation, respectively; $V_{0}$ is the pre-atmospheric velocity of a meteoroid; $\rho$ is the air density, and $\lambda$ is the heat conductivity of the meteoroid; $\delta_{\mathrm{m}}$ is the mineralogical density of the meteoroid, $c$ is the specific heat of the meteoroid, $b=1 / H$ is the air density gradient, and $Z_{\mathrm{R}}$ is the zenith distance of the radiant.

The right-hand terms of Eq. (1) includes directly measurable quantities derived from photographic observations and the standard atmosphere ( $\rho$ and $b$ according to the observed height of meteor occurrence).

According to Levin (1956), the heat transfer coefficient $\Lambda$ of stone meteoric particles equals 1 and for those of iron equals 0.75 ; the temperature of a meteoroidal frontal surface at the beginning height equals $1600 \mathrm{~K}$ for friable stone particles, $2400 \mathrm{~K}$ for dense stone particles, and $2800 \mathrm{~K}$ for iron particles. Spurny et al. (2000) emphasized that the meteoroid material begins to sublimate at the surface when the surface temperature reaches about $2200 \mathrm{~K}$ thus confirming Levin's results.

In Table 1 , laboratory data for $\delta_{\mathrm{m}}, c$, and $\lambda$ are given for a series of rocks, minerals, and metals as taken from Berch et al. (1949). Using these data on $\delta_{\mathrm{m}}, \lambda$ and $c$, and assuming the values of $T_{B}$ and $\Lambda$ of Levin (1956), we are able to construct the following dependence of the function $f\left(\delta_{\mathrm{m}}\right)$ on $\delta_{\mathrm{m}}$ :

$f\left(\delta_{\mathrm{m}}\right)=\log \left[\frac{2 T_{B}\left(\lambda \delta_{\mathrm{m}} c\right)^{1 / 2}}{\Lambda}\right]$.

The values of the mineralogical density $\delta_{\mathrm{m}}$ and the corresponding function $f\left(\delta_{\mathrm{m}}\right)$ used by Benyuch (1968) to measure the dependence $f\left(\delta_{\mathrm{m}}\right)$ for different materials are given in Table 1.

Calculating the value of

$f\left(\delta_{\mathrm{m}}\right)=\log \left[V_{0}^{5 / 2} \rho\left(b \cos Z_{R}\right)^{-1 / 2}\right]$,

from photographic observations and for a standard atmosphere, and using the diagram of the function $f\left(\delta_{\mathrm{m}}\right)$ (Fig. 1) plotted at the base of Table 1 , we are able to determine directly the mineralogical density $\delta_{\mathrm{m}}$ of a meteoroid.

Using this method, Benyuch (1974) estimated mineralogical densities of meteoroids from the database of 2643 meteors

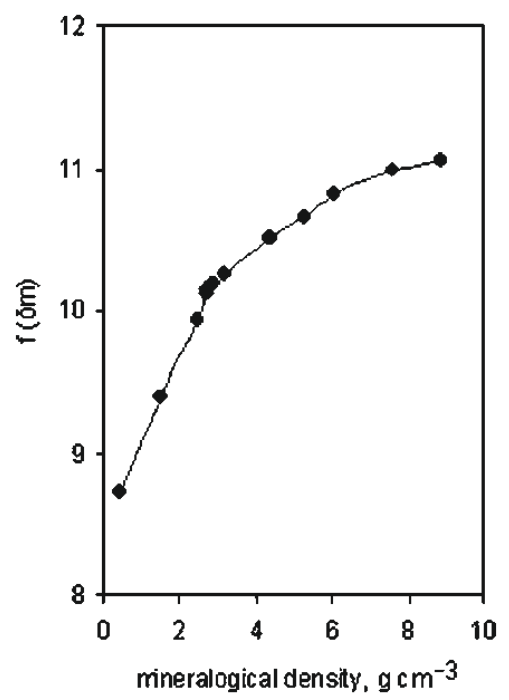

Fig. 1. The dependence of the function $f\left(\delta_{\mathrm{m}}\right)$ on $\delta_{\mathrm{m}}$.

photographed with Super-Schmidt cameras (McCrosky \& Posen 1961) and 379 meteors registered with NAFA 3C/25 cameras $(D=100 \mathrm{~mm}, F=250 \mathrm{~mm})$ in Dushanbe and Odessa (Babadzhanov \& Kramer 1963), and Kiev (Benyuck et al. 1980). Hereafter, Benyuch took into account that, according to the investigations of Ceplecha (1967), the beginning heights of meteors photographed by Super-Schmidt cameras correspond to the theoretical heights of meteor appearance defined by Levin (1956). However, she also took into account that, according to Katasev (1966), the beginning heights of meteors photographed by $N A F A 3 \mathrm{C} / 25$ cameras are on average $5 \mathrm{~km}$ less than those photographed by Super-Schmidt cameras. Therefore, for calculating $f\left(\delta_{\mathrm{m}}\right)$ the beginning heights of meteors photographed by $N A F A$ C $/ 25$ cameras were increased by $5 \mathrm{~km}$.

The mean mineralogical densities $\delta_{\mathrm{m}}$ of meteoroids belonging to different meteor streams and sporadic background estimated by Benyuch (1974), are given in the third and fourth columns of Table 2, where $N_{\mathrm{m}}$ is the number of meteors used in determining $\delta_{\mathrm{m}}$.

From television observations, it was found that for fast fireballs, for example Leonid fireballs with initial velocities of $70 \mathrm{~km} \mathrm{~s}^{-1}$, the process of ablation starts at extreme beginning heights (till $200 \mathrm{~km}$ ) (see e.g. Spurny et al. 2000). However, at such high altitudes, ablation does not depend on the temperature 
Table 2. Densities and porosities of meteoroids.

\begin{tabular}{|c|c|c|c|c|c|c|c|c|}
\hline $\begin{array}{l}\text { Meteor } \\
\text { stream }\end{array}$ & $\begin{array}{l}\text { Parent } \\
\text { body }\end{array}$ & \multicolumn{2}{|c|}{$\begin{array}{cc}\delta_{\mathrm{m}}, \mathrm{g} \mathrm{cm}^{-3} & N_{\mathrm{m}} \\
\text { Benyuch (1974) }\end{array}$} & \multicolumn{2}{|c|}{$\begin{array}{c}\delta_{\mathrm{m}}, \mathrm{g} \mathrm{cm}^{-3} N_{\mathrm{m}} \\
\text { This work }\end{array}$} & \multicolumn{2}{|c|}{$\begin{array}{l}\delta, \mathrm{g} \mathrm{cm}^{-3} N_{\mathrm{b}} \\
\text { This work }\end{array}$} & $\begin{array}{l}p, \\
\%\end{array}$ \\
\hline & 21P/Giacobini-Zinner & 1.8 & 175 & - & - & $0.3^{* *}$ & - & 83 \\
\hline Leonids & 55P/Tempel-Tutlle & - & - & $2.3 \pm 0.2$ & 10 & $0.4 \pm 0.1$ & 6 & 83 \\
\hline Orionids & 1P/Halley & - & - & $2.4 \pm 0.2$ & 6 & $0.9 \pm 0.5$ & 2 & 62 \\
\hline Perseids & 109P/Swift-Tutlle & 2.4 & 309 & $2.25 \pm 0.04$ & 191 & $1.2 \pm 0.2$ & 97 & 45 \\
\hline Taurids & 2P/Encke & 2.7 & 63 & $2.7 \pm 0.2$ & 12 & $1.6 \pm 0.4$ & 6 & 41 \\
\hline Quadrantids & 2003EH1 and 96P/Machholz1 & 3.4 & 20 & $3.4 \pm 0.8$ & 4 & $1.9 \pm 0.2$ & 3 & 44 \\
\hline$\alpha$-Capricornids & 2003EX12 = 169P/NEAT & 2.8 & 34 & $3.4 \pm 0.8$ & 5 & 2.1 & 1 & 38 \\
\hline$\kappa$-Cygnids & 2008ED69? & - & - & $2.5 \pm 0.1$ & 2 & $2.2 \pm 1.7$ & 2 & 12 \\
\hline$\delta$-Aquarids & 2003EH1 and 96P/Machholz1 & 4.1 & 36 & $3.4 \pm 0.4$ & 13 & $2.4 \pm 0.6$ & 8 & 29 \\
\hline Geminids & 3200 Phaethon & 3.3 & 118 & $2.9 \pm 0.2$ & 20 & $2.9 \pm 0.6$ & 8 & 0 \\
\hline Sporadic & & 2.7 & 2267 & $3.0 \pm 0.1$ & 238 & $1.8 \pm 0.3$ & 103 & 40 \\
\hline
\end{tabular}

** The value of the bulk density is taken from Borovička et al. (2007).

of the meteoroid surface because the temperature remains low and the meteoroidal body is heated insufficiently. The ablation process is provided by the sputtering of meteoroid surface by incoming atmospheric atoms and molecules and is effective for fast meteors before the meteoroid surface reaches boiling temperature (Borovička 2006).

Following the aforementioned technique, we determined the mineralogical densities of 501 meteoroids from photographic observations of meteors completed during the years 1957-1983 in Dushanbe, Kiev, and Odessa. The results of calculating $\delta_{\mathrm{m}}$ and their standard deviations for meteoroids belonging to different streams and sporadic background, and the number $N_{\mathrm{m}}$ of meteors used in determining the mean values of mineralogical densities given in the five and sixth columns of Table 2, are in satisfactory agreement with the results of Benyuch (1974). The dependence of mineralogical densities on beginning heights for meteoroids of different showers is plotted in Fig. 2a and for Perseid meteoroids - in Fig. 2b, which shows that the meteoroids of smaller mineralogical densities appear at higher altitudes.

Sixty percent of Perseid meteoroids have mineralogical densities in the range $2-3 \mathrm{~g} \mathrm{~cm}^{-3}$ and $35 \%$ in the range $1-2 \mathrm{~g} \mathrm{~cm}^{-3}$. The mean value of the mineralogical density of Perseid meteoroids is equal to $\delta_{\mathrm{m}}=2.25 \pm 0.04$. The beginning height of $134.5 \mathrm{~km}$ for a single Perseid meteoroid with a mineralogical density of $\delta_{\mathrm{m}}=0.45 \mathrm{~g} \mathrm{~cm}^{-3}$ was found to have a high uncertainty because the small value of the angle $Q$ of the two planes equals $4.6^{\circ}$. Therefore, we consider that this value of $\delta_{\mathrm{m}}$ was determined with low accuracy.

Eleven Perseid meteoroids were found to have a mineralogical density $\delta_{\mathrm{m}}$ of more than $3 \mathrm{~g} \mathrm{~cm}^{-3}$. Probably the material of these cometary meteoroids contains much solid inclusions which relate to $C I$ and $C M$ carbonaceous chondrites consistent with the $C I$ and $C M$ meteorite composition. The existence of these ingredients was confirmed by Borovička (2006) also in the material of Leonid meteoroids. The investigation of dust particles from comet $81 \mathrm{P} /$ Wild- 2 captured by the Stardust spacecraft supports this fact. The crystalline fragments found in these dust particles are identical to minerals contained in the material of meteorites broken up from asteroids and relate to $C I$ and $C M$ carbonaceous chondrites (Flynn et al. 2006; Zolensky et al. 2006; Zolensky 2008).

\section{Bulk density of meteoroids}

Among the different forms of meteoroidal fragmentation in the Earth's atmosphere the quasi-continuous fragmentation is the most effective and is there of foremost interest. According to
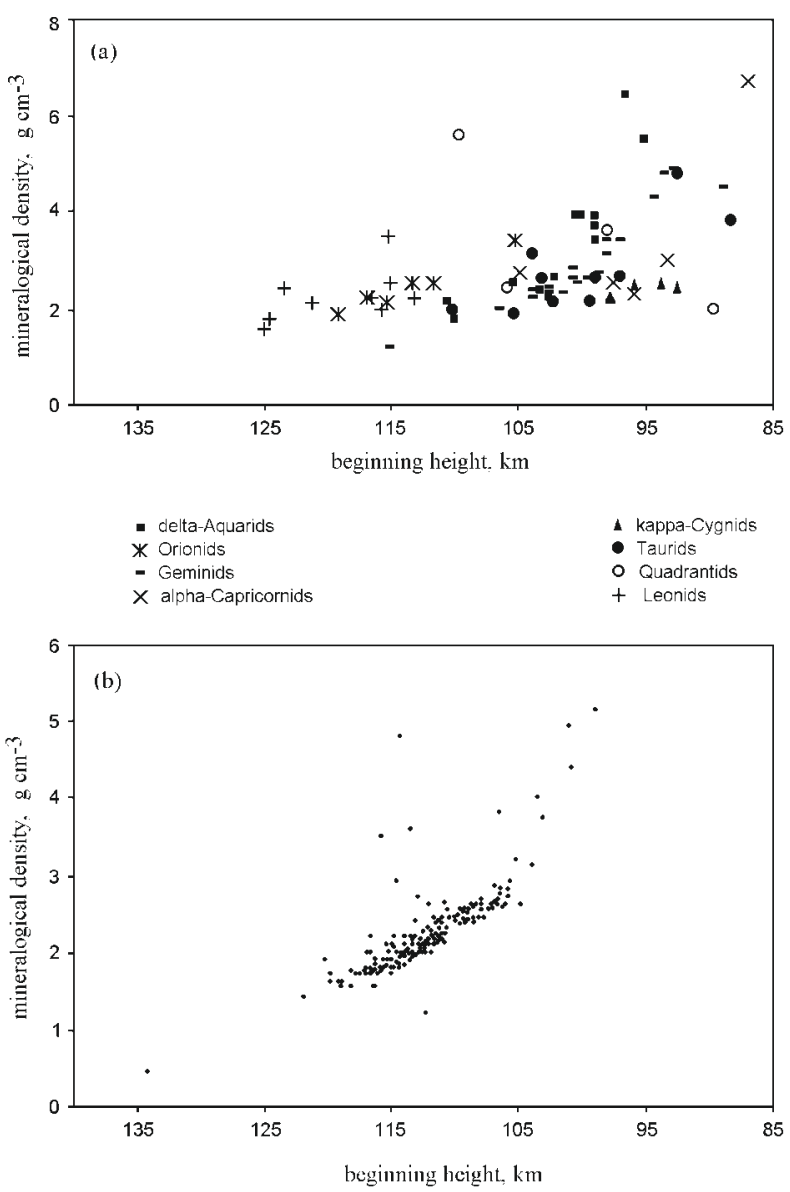

Fig. 2. Mineralogical density as a function of beginning height: a) for meteoroids of different meteor showers, and b) - for Perseid meteoroids.

the theory of quasi-continuous fragmentation (Lebedinets 1980; Novikov et al. 1984; Babadzhanov et al. 1988; Babadzhanov 2002), it is possible to obtain the following expression that describes the meteor luminosity along its visible trajectory and its dependence on atmospheric density and parameters of quasicontinuous fragmentation:

$$
\begin{aligned}
& I(\rho)=\frac{9 \tau_{v} M_{0} V_{0}^{3} \cos Z_{R}}{2 H\left(R_{0} R_{1}\right)^{3}}\left\{F_{1}(\rho) \Theta(a-\rho)\right. \\
& \left.+R_{1}^{3} F_{2}(\rho) \Theta(\rho-a) \Theta(b-\rho)+\frac{1}{30} F_{3}(\rho) \Theta(\rho-b) \Theta\left(\rho_{e}-\rho\right)\right\},
\end{aligned}
$$


where

$$
\begin{aligned}
& F_{1}(\rho)= \rho\left\{\frac{1}{3}\left(\rho_{e}-\rho\right)^{2}\left[R_{1}^{3}-(a-\rho)^{3}\right]\right. \\
&\left.-\frac{1}{2}\left(\rho_{e}-\rho\right)\left[R_{1}^{4}-(a-\rho)^{4}\right]+\frac{1}{5}\left[R_{1}^{5}-(a-\rho)^{5}\right]\right\}, \\
& F_{2}(\rho)= \rho\left\{\frac{1}{3}\left(\rho_{e}-\rho\right)^{2}-\frac{1}{2} R_{1}\left(\rho_{e}-\rho\right)+\frac{1}{5} R_{1}^{2}\right\}, \\
& F_{3}(\rho)= \rho\left(\rho_{e}-\rho\right)^{5}, \\
& a=\rho_{e}-R_{0}, \quad b=\rho_{e}-R_{1},
\end{aligned}
$$

$I(\rho)$ is the meteor luminosity at the height where the atmospheric density is equal to $\rho ; \tau_{v}, M_{0}, V_{0}$ are the luminous efficiency, preatmospheric meteoroid mass, and velocity, respectively; $H$ is the scale height; $Z_{R}$ is the zenith distance of the meteor radiant; $\rho_{e}$ is the atmospheric density at the end height of the meteor phenomenon:

$\rho_{e}=2 \rho_{\mathrm{m}}+0.75 R_{1}+\sqrt{\rho_{\mathrm{m}}^{2}-0.0375 R_{1}^{2}}$

deduced from a condition that the maximum of the light curve is in the range $a \leq \rho_{\mathrm{m}} \leq b ; \rho_{\mathrm{m}}$ is the atmospheric density at the height of maximum luminosity, and $\rho$ is the atmospheric density at an arbitrary point in the meteor trajectory; $a$ is the atmospheric density at the height of complete evaporation of fragments released at the moment of fragmentation beginning, while $b$ is the atmospheric density at the height of the end of fragmentation; $R_{0}$ and $R_{1}$ are the parameters determining the quasi-continuous fragmentation:

$R_{0}=\frac{6 Q_{f} M_{0}^{1 / 3} \delta^{2 / 3} \cos Z_{R}}{\Lambda A H V_{0}^{2}}$,
$R_{1}=\frac{2\left(Q-Q_{f}\right) m_{0}^{1 / 3} \delta_{\mathrm{m}}^{2 / 3} \cos Z_{R}}{\Lambda^{\prime} A^{\prime} H V_{0}^{2}}$.

$Q_{f}=2 \times 10^{10} \mathrm{erg} \mathrm{g}^{-1}$ (Hawkes \& Jones 1975; Kruchinenko 1982) being the specific energy of meteoroid fragmentation, while $Q=8 \times 10^{10} \mathrm{erg} \mathrm{g}^{-1}$ is the specific energy of heating and evaporation of meteoric matter; $\Lambda, A$, and $\delta$ are the heat transfer coefficient, the shape factor, and the meteoroid density, respectively; $\Lambda^{\prime}, A^{\prime}$, and $\delta_{\mathrm{m}}$ have the same values for the fragments; $m_{0}$ is the fragment mass; and $\Theta(x)$ is Heavyside's unit step function: $\Theta(x)=1$ at $x>0$ and $\Theta(x)=0$ at $x \leq 0$.

To determine the meteoroid bulk densities, we used the data collected on the pre-atmospheric masses and velocities, the zenith distances of radiants, and the light curves of 501 meteors registered by dint of the double-station photographic observations with the cameras NAFA $3 \mathrm{C} / 25$ in Dushanbe (Tajikistan) (Babadzhanov 2006), Kiev, and Odessa (Ukraine) (Benyuch et al. 1980; Kramer \& Shestaka 1982). In these works the initial photometric masses $M_{0}$ were computed from

$M_{0}=2 \int_{t_{e}}^{t_{b}} \frac{I \mathrm{~d} t}{\tau V^{2}}$,

where the luminous efficiency $\tau$ was assumed to be $\tau=\tau_{0} V$, and $\log \tau_{0}=-9.30 ; I$ and $V$ are the luminosity and velocity at an arbitrary point of the meteor trajectory, $I=10^{-0.4 \mathrm{M}}, \mathrm{M}$ is the absolute (100 km distance) magnitude at the same point, and $t_{b}$ and $t_{e}$ are the time of meteor appearance and disappearance, respectively.

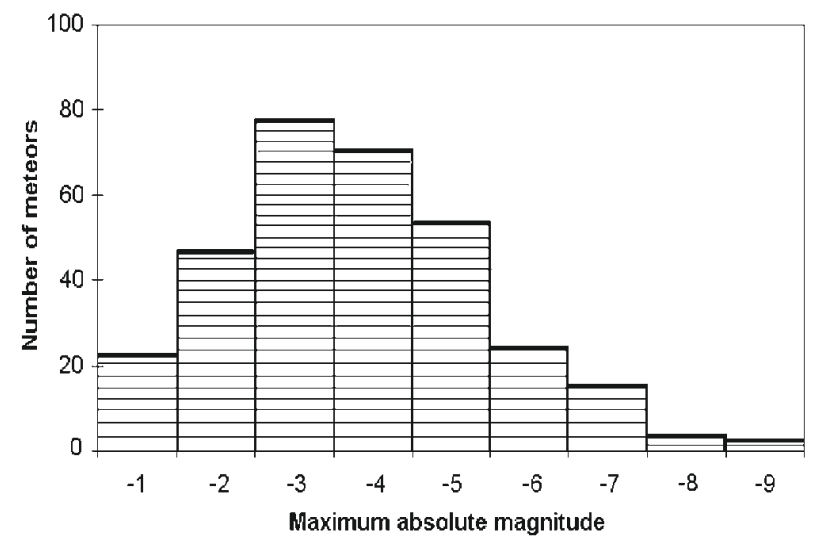

Fig. 3. The distribution of maximum absolute magnitudes for investigated meteors.

The initial velocity of meteors $V_{0}$ was determined by the following interpolation formula

$V=b+k c \exp ^{k t}$

where $b, k$, and $c$ are constants derived from the least-squares solution, and $b$ corresponds to the initial velocity $V_{0}$. From photographic observations of meteors with the NAFA 3C/25 cameras, the initial velocity is determined with a standard deviation uncertainty of no more than 2-3\%. In deriving the bulk density of the corresponding meteoroid from meteor data, we used the values of mineralogical density $\delta_{\mathrm{m}}$ determined for each meteoroid.

The meteoroid bulk density and masses of fragments can be estimated if the values of $\Lambda, \Lambda^{\prime}, A$, and $A^{\prime}$ are known apriori. Meteors photographed in Dushanbe, Kiev, and Odessa are bright and produced by meteoroids of mass higher than $0.01 \mathrm{~g}$. Figure 3 shows the distribution of the maximum absolute magnitudes of meteors under investigation. According to Lebedinets (1991), large meteoroids with masses between $0.01 \mathrm{~g}$ and $10 \mathrm{~g}$ have a heat transfer coefficient that depends on mass $M_{0}$ according to

$\Lambda=\Lambda_{0}+\left(1-\Lambda_{0}\right) \exp \left(-k M_{0}\right)$

where $\Lambda_{0}=0.03, k=0.25 \mathrm{~g}^{-1}$, and it is assumed that $A=$ $1.5, A^{\prime}=1.21, H=6 \mathrm{~km}$, and $\Lambda^{\prime}=1$.

Using the observed values of $M_{0}, V_{0}$, and $Z_{R}$, the light curves of meteors, and the method of successive approximations, we determined the values of meteoroid bulk densities for which the theoretical and observed meteor light curves are in closest agreement.

Simulations of the meteor light curves were carried out for meteoroid bulk densities between $10^{-3}$ and $10 \mathrm{~g} \mathrm{~cm}^{-3}$ and a mass of fragments between $10^{-10}$ and $10^{-2} \mathrm{~g}$. The meteoroid bulk density at which the mean difference between the theoretical and observational light curves reached a minimum, was adopted to be the most reliable. As an example, Fig. 4 shows the results of simulations of light curves for two meteors No. 584865 and No. 221, photographed in Dushanbe and Odessa, respectively, where the meteor absolute magnitude $m g$ is plotted versus height.

An analysis of our results shows that the observed parameters and light curves of 236 out of 501 bright meteors photographed in Dushanbe, Kiev, and Odessa, are described sufficiently well by the theory of quasi-continuous fragmentation. This is $47 \%$ of the total number of investigated meteors. It was impossible to simulate the light curves of 265 meteors $(53 \%)$ 

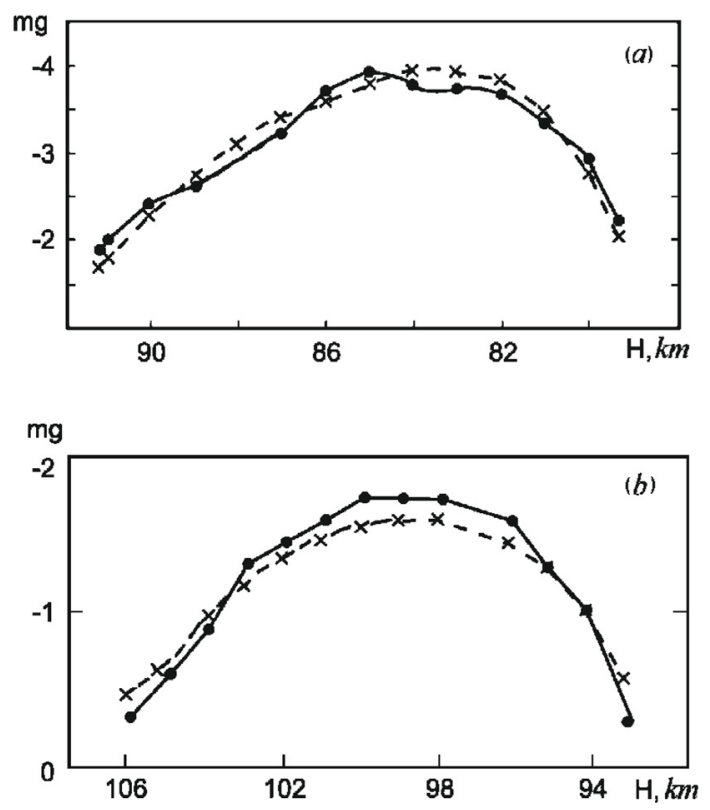

Fig. 4. Observed (dots) and theoretical (crosses) light curves of the meteors: a) No. 584865 , Sporadic, $M_{0}=2.10 \mathrm{~g}, V_{0}=43.1 \mathrm{~km} \mathrm{~s}^{-1}$ $\cos Z_{R}=.794$; b) No. 221, Perseid, $M_{0}=0.08 \mathrm{~g}, V_{0}=61.5 \mathrm{~km} \mathrm{~s}^{-1}$, $\cos Z_{R}=0.880$.

within the framework of the theory of quasi-continuous fragmentation. These meteors were probably produced by meteoroids that undergo another type of fragmentation, for which more complicated simulations are necessary.

The results of determining the mean bulk densities $\delta$ and their standard deviations for meteors belonging to different streams and sporadic background are given in Table 2, where $N_{\mathrm{b}}$ is the number of meteors used in determining the mean values of bulk densities. The Geminid meteoroids are found to have the highest bulk density average of $2.9 \mathrm{~g} \mathrm{~cm}^{-3}$, which agrees with the results of Ceplecha \& McCrosky (1992) obtained from photographic observations taking into account the "gross" fragmentation of meteoroids. In contrast, the Leonid meteoroids have the lowest average bulk density equal to $0.4 \mathrm{~g} \mathrm{~cm}^{-3}$. The mean bulk densities of meteoroids of other streams are between 0.9 and $2.4 \mathrm{~g} \mathrm{~cm}^{-3}$ and that of sporadic meteoroids equals $1.8 \mathrm{~g} \mathrm{~cm}^{-3}$.

According to the model of quasi-continuous fragmentation we measured the bulk densities of meteoroids and found that the mean masses of fragments separated from meteoroids are in the range $10^{-5}-10^{-6} \mathrm{~g}$, and their mean sizes vary between $40 \mu \mathrm{m}$ and $110 \mu \mathrm{m}$. We propose that fragments of these sizes are the constituent parts of meteoroids. Our measurement of fragment sizes is similar to those of Simonenko (1967) and Borovička et al. (2007), who estimated that the sizes of fragments escaping from meteoroids during meteor flares are in the range $30 \mu \mathrm{m}<$ $r_{0}<110 \mu \mathrm{m}$.

Measurements of the mean bulk density of meteoroids derived in this paper for the entire collection of photographic observations of bright meteors in Tajikistan and Ukraine confirm the results of Babadzhanov (2002) for only 111 meteors observed in Dushanbe.

\section{Porosity of meteoroids}

From data of Table 2, it follows that the bulk densities of meteoroids are considerably lower than mineralogical densities of meteoroids. We suggest that this difference may be explained by the porosity of meteoroids.

The bulk density $\delta$ is related to mineralogical density $\delta_{\mathrm{m}}$ by the expression

$\delta=\delta_{\mathrm{m}}(1-p)$

where $p$ is the porosity.

Results of the estimation of meteoroids' porosity determined according to Eq. (14) are given in the last column of Table 2, where the value of the bulk density of Draconid meteoroids is taken from Borovička et al. (2007). Table 2 shows that the porosity of meteoroids in the streams under review and in the sporadic background varies from 0 to $83 \%$.

The Geminid meteoroids have the lowest porosity, while the Leonid meteoroids are the most porous (83\%). Assuming a mineralogical density of close to $3 \mathrm{~g} \mathrm{~cm}^{-3}$ and using a typical Draconid bulk density of about $0.3 \mathrm{~g} \mathrm{~cm}^{-3}$, Borovička et al. (2007) found the porosity of Draconid meteoroids to equal $90 \%$. To estimate the porosity of Draconid meteoroids, we used the mean value of mineralogical density obtained by Benyuch (1974) and a typical Draconid bulk density value of $0.3 \mathrm{~g} \mathrm{~cm}^{-3}$ used by Borovička (2007). The porosity of Draconid meteoroids was found to equal $83 \%$, which is identical to the porosity of the Leonid meteoroids. These results were expected because the Draconid meteoroids are produced by the activity of the comet $21 \mathrm{P} /$ Giacobini-Zinner, and represent the most fragile and porous of cosmic material (Jacchia et al. 1950; Jacchia 1955; Ceplecha 1968, 1988; Borovička et al. 2007). The comet 55P/Tempel-Tuttle is the parent body of the Leonid meteoroids belonging to the group IIIB, which is typical of the most fragile and porous interplanetary bodies of cometary origin (see e.g. Ceplecha 1977, 1994; Spurny et al. 2000). These results confirm the conclusion that cometary meteoroids are effectively grain aggregates of low bulk density and high porosity (Borovička 2006).

The Quadrantid and $\delta$-Aquarid meteoroids have equal values of the mineralogical densities $\left(3.4 \mathrm{~g} \mathrm{~cm}^{-3}\right)$, but their bulk densities differ from each other. This is probably due to the perihelion distance of the $\delta$-Aquarids, as of the Geminids, being smaller i.e. closer to the Sun, than for the Quadrantids. The perihelion distances of orbits of the $\delta$-Aquarids and Quadrantids equal $q=$ $0.07 \mathrm{AU}$ and $q=0.98 \mathrm{AU}$, respectively.

According to the theoretical findings of ReVelle (2001), the porosity of meteoroids is between 0 and $91 \%$. The measurements of the mineralogical and bulk densities of samples of carbonaceous and ordinary chondrites not destroyed under atmospheric influences indicate that they have significant porosity of between 0 and 35\% (Consolmagno \& Britt 1998; Consolmagno et al. 2008), while the porosity of interplanetary dust particles reaches 90\% (Flynn et al. 1999; Rietmeijer \& Nuth 2000).

Our measurements of meteoroidal porosity from photographic observations of meteors are in good agreement with the aforementioned laboratory porosity measurements of carbonaceous and ordinary chondrites and interplanetary dust particles, and confirm the porous structure of meteoroidal parent bodies i.e. comets and asteroids.

\section{Conclusions}

On the basis of data for the beginning heights, pre-atmospheric velocities, and zenith distances of the radiants of 501 meteoroids from photographic observations of meteors in Dushanbe, Kiev, and Odessa completed during 1957-1983, we have determined 
the mineralogical densities of these meteoroids. The derived mean mineralogical densities of meteoroids belonging to different streams vary between $2.2 \mathrm{~g} \mathrm{~cm}^{-3}$ (Perseids) and $3.4 \mathrm{~g} \mathrm{~cm}^{-3}$ (Quadrantids, $\delta$-Aquarids and $\alpha$-Capricornids). According to the theory of quasi-continuous fragmentation of meteoroids, we have analyzed the light curves of the same 501 bright meteors and estimated the bulk densities of 236 meteoroids that are experiencing quasi-continuous fragmentation. The mean bulk densities of meteoroids measured for different streams vary between $0.4 \mathrm{~g} \mathrm{~cm}^{-3}$ (Leonids) and $2.9 \mathrm{~g} \mathrm{~cm}^{-3}$ (Geminids), a range that corresponds to the bulk densities of the II, IIIA, and IIIB groups of meteoroids according to the classification of Ceplecha \& McCrosky (1976) and Ceplecha (1988). The porosity of meteoroids in the streams under review and in the sporadic background varies from 0 to $83 \%$, and these estimations are in good agreement with the experimental results and results obtained by other methods, thus confirming the porous structure of meteoroidal parent bodies i.e. comets and asteroids.

Acknowledgements. The authors would like to express their gratitude to Dr. J. Borovička and to the anonymous referee for discussion of the obtained results and useful comments which improved the paper. The annotations by the English copy editor of A\&A is also appreciated. This work was supported by the International Science and Technology Center Project T-1086.

\section{References}

Babadzhanov, P. B. 2002, A\&A, 384, 317

Babadzhanov, P. B. 2006, Summary catalogue of orbital elements and light curves of the meteors photographed in the Institute of Astrophysics, Tajik Academy of Sciences (Dushanbe), Dushanbe, Donish, 207

Babadzhanov, P. B., \& Kramer, E. N. 1963, Methods and some results of photographic researches of meteors, Publishing house of the Ac. of Sci. of the USSR, Moscow, 142, in Russian

Babadzhanov, P. B., Novikov, G. G., Lebedinets, V. N., \& Blokhin, A. V. 1988, Astron. Vestn., 27, 71

Benyuch, V. V. 1968, Vestnik KGU. Seriya astronomii, 10, 51

Benyuch, V. V. 1974, Ph.D. Dissertation Fotometricheskoe issledovanie meteorov i plotnost' meteornych tel, Kiev, 148

Benyuch, V. V., Kruchinenko, V. G., \& Sherbaum, L. M. 1980, Astrometriya \& Astrofiizika, 41, 68; 1981, 42, 41 (Kiev: Naukova Dumka)

Berch, et al. 1949, Spravochnik dlya geologov po fizicheskim constantam, Moscow, Inostr. literatura

Borovička, J. 2006, In Asteroids, Comets, Meteors 2005, ed. D. Lazzaro, S. Ferraz-Mello, \& J. A. Fernandez, Proc. IAU Symp., 229, 249

Borovička, J., Spurny, P., \& Koten, P. 2007, A\&A, 473, 661
Bronshten, V. A. 1981, Physics of meteor phenomena (Moscow: Nauka) Ceplecha, Z. 1958, Bull. Astron. Inst. Czech. Ac. of Sci., 9, 4, 154 Ceplecha, Z. 1967, Smiths. Contr. Astrophys., 11, 35

Ceplecha, Z. 1968, Smiths. Astrophys. Obs. Spec. Rep., 279

Ceplecha, Z. 1977, In Comets, Asteroids, Meteorites, ed. A. H. Delsem, Toledo, Ohio, 143

Ceplecha, Z. 1988, Bull. Astr. Inst. Czechosl., 39, 221

Ceplecha, Z. 1994, In Asteroids, Comets, Meteors 1993, ed. A. Milani et al. (Dordrecht, The Netherlands: Kluwer Acad. Publishers), 343

Ceplecha, Z. 1995, Earth, Moon, Planet, 68, 107

Ceplecha, Z., \& McCrosky, R. E. 1976, J. Geophys. Res., 81, 6257

Ceplecha, Z., \& McCrosky, R. E. 1992, In Asteroids, Comets, Meteors 1991, ed. A. W. Harris, \& E. Bowell, Lunar and Planet. Inst., Houston, 109

Ceplecha, Z., Spurny, P., Borovička, J., et al. 1993, A\&A, 279, 615

Consolmagno, G. J., \& Britt, D. T. 1998, Meteor. Planet. Sci., 33, 1231

Consolmagno, G. J., Britt, D. T., \& Macke, R. J. 2008, LPI Contribution No. 1391,1582

Flynn, G. J., Moore, L. B., \& Klock, W. 1999, Icarus, 142, 97

Flynn, G. J., Bleuet, P., Borg, J., et al. 2006, Science, 314, 1731

Hawkes, R. L., \& Jones, J. 1975, MNRAS, 175, 339

Jacchia, L. G. 1955, ApJ, 121, 521

Jacchia, L. G., Kopal, Z., \& Millman, P. M. 1950, ApJ, 111, 104

Jacchia, L., Verniani, F., \& Briggs, R. E. 1967, Smithson. Contr. Astrophys., 10,1

Katasev, L. A. 1966, Issledovanie meteorov v atmosfere Zemli fotograficheskim metodom (Leningrad: Gidrometeoizdat)

Kramer, E. N., \& Shestaka, I. S. 1982, Resultaty fotograficheskih nabludenij meteorov po programmam MGG, MGSS, MGAS, Katalog, Moscow

Kruchinenko, V. G. 1982, in Meteornoe Veshchestvo v Mezhplanetnom Prostranstve, ed. O. I. Belkovich, P. B. Babadzhanov, V. A. Bronshten, N. I. Sulejmanov, Moscow-Kazan, 183

Lebedinets, V. N. 1980, Pyl' v Verkhnej Atmosfere i Kosmicheskom Prostranstve, Meteory (Leningrad: Gidrometizdat)

Lebedinets, V. N. 1991, Astron. Vestn., 25, 200

Levin, B. Yu. 1956, Physical Theory of Meteors and Meteor Matter in the Solar System, USSR Academy of Sciences, Moscow

Levin, B. Yu. 1962, Bull. Komissii po kometam i meteoram, 6, 3

Levin, B. Yu. 1963, AZh, 40, 304

McCrosky, R. E., \& Posen, A. 1961, Smiths. Contr. Astrophys., 5, No. 4, 29

Novikov, G. G., Lebedinets, V. N., \& Blokhin, A. V. 1984, Pisma v AZh, 10, 71

ReVelle, D. O. 2001, in Proc. Meteoroids 2001 Conf., ed. B. Warmbein, ESA-SP 495,513

Rietmeijer, F. J. M., \& Nuth III, J. A. 2000, Earth. Moon and Planets, 82, 325 Simonenko, A. N. 1967, Kometu i meteoru, 15, 34

Spurny, P., Betlem, H., van’t Leven, J., \& Jenniskens, P. 2000, Meteor. Planet. Sci., 35, 243

Verniani, F. 1967, Smithson. Contr. Astrophys., 10, 181

Verniani, F. 1969, Space Sci. Rev., 10, 230

Verniani, F. 1973, Geophys. Res., 78, 8429

Zolensky, M. E. 2008, LPI Contribution No. 1405, 8155

Zolensky, M. E., Zega, T. J., Yano, H., et al. 2006, Science, 314, 1735 